\title{
Erratum
}

\section{Inequalities: Theory of Majorization and Its Applications}

\author{
Albert W. Marshall, Ingram Olkin, Barry C. Arnold \\ A.W. Marshall et al., Inequalities: Theory of Majorization and Its Applications, \\ Springer Series in Statistics, DOI 10.1007/978-0-387-68276-1, \\ (C) Springer Science+Business Media, LLC 2011
}

\section{DOI 10.1007/978-0-387-68276-1_21}

On page 566 in the display, 5 lines from the bottom of the page, at the end of the display

IS : $\prod_{i=1}^{k}\left(\frac{N}{N}\right)^{x_{i}}$

SHOULD BE : $\prod_{i=1}^{k}\left(\frac{x_{i}}{N}\right)^{x_{i}}$ 